\title{
SISTEMA CLIENTELAR, MEDIACIONES Y ELECCIONES De AlCalde DURANTE el Siglo XXI en Cartagena DE INDIAS (DOCUMENTO DE TRABAJO)
}

\author{
CLIENTELISM, MEDIATIONS AND ELECTIONS FOR MAYOR DURING XXI CENTURY
}

IN CARTAGENA DE INDIAS

Por: Mercedes Posada Meola*

MERCEDES POSADA

MEOLA*

Comunicadora Social, magíster en Desarrollo Social. Actualmente cursa un doctorado en Comunicación en la Universidad Nacional de

La Plata y es investigadora

del grupo, Cine, Historia

Cultura de la Universidad de Cartagena.
Artíclo Recibido: 11 marzo 2013. Artículo Aprobado: 29 abril 2013

\section{RESUMEN}

Este trabajo se encuentra en proceso de elaboración y se inscribe en la producción del Proyecto de Doctorado en la Universidad Nacional de La Plata, Argentina.

La investigación se pregunta por las relaciones entre el sistema clientelar institucionalizado en Cartagena de Indias, las retóricas que entran en tensión durante las campañas políticas y el sostenimiento de un modelo que parece renovarse en cada proceso electoral. La presunción se adscribe en la dimensión medios de comunicación y democracia y establece un vínculo entre los diferentes actores que confluyen alrededor de la comunicación política: ciudadanía, partidos políticos, candidatos, elecciones, estado y medios de comunicación (Bonilla, 2003).

Palabras clave: Comunicación política, sistema clientelar, elecciones, ciudadanía y democracia.

\section{ABSTRACT}

This is a paper in process of final elaboration and it fits in the production of the project for a doctoral degree at Universidad Nacional de La Plata, Argentina.

The research starts with a suspicion that questions the relationship between the clientelism system institutionalized in Cartagena de Indias, the rhetoric that comes in tension during political campaigns and the maintenance of a model that seems to be renewed in each electoral process. The presumption is ascribed in the dimension of social media and a democracy and establishes a link between the different actors that converge around the political communication: citizenship, political parties, candidates, elections, state and media (Bonilla, 2003).

Key words: Political Communication, patronage systems, elections, citizenship and democracy. 


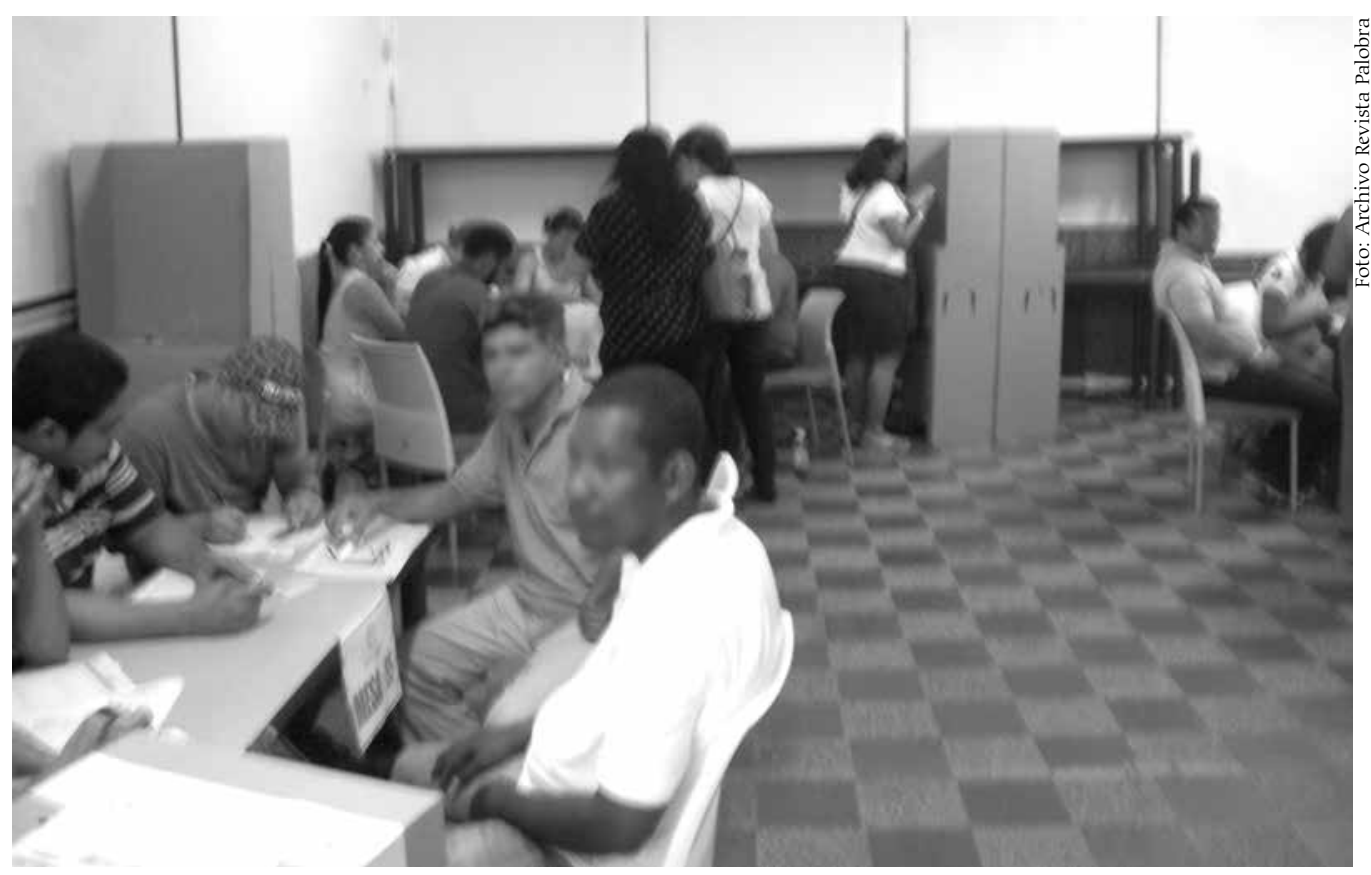

Jornadas electorales 2013.

\section{La cuestión del clientelismo político (breve estado del arte)}

Estudiar un tema tan institucionalizado en nuestros sistemas democráticos como el clientelismo político supone un proceso de lectura, selección y descarte que se irá refinando a lo largo de esta investigación. No obstante, por ahora vale la pena mencionar una serie de trabajos que sirven como punto de partida para explorar el tema.

Así por ejemplo, es importante tener como referente la investigación realizada por la doctora Susana Corzo Fernández (2002) quien estudia el concepto de clientelismo político diferenciándolo de otros fenómenos confundidos con él, como la corrupción, el voto cautivo, el tráfico de influencias y el caciquismo. Su trabajo analiza esta práctica como una relación de intercambio y en tal sentido, describe la estructura de la relación clientelar en los diferentes ámbitos de la política en donde se dispone de recursos públicos (y no solo dineros públicos) que puedan utilizarse como contenido de dicho intercambio.

Temporal y espacialmente, la investigación de Corzo propone un recorrido que pasa por las relaciones establecidas entre los ciudadanos de la Roma antigua y luego se remite a las relaciones de caciquismo como un sistema de dominación (o de relación no libre) practicado en las diferentes regiones de España. En este punto aclara que si bien el caciquismo está emparentado con el clientelismo, no se trata de un mismo fenómeno. Esta distinción es importante ya que 
aporta pistas conceptuales para delimitar el modo de abordar el clientelismo y particularmente el clientelismo político.

Una de las particularidades de esta investigación es que cambia la mirada desde la cual ha sido comúnmente estudiado el clientelismo y se permite exponer las funcionalidades de un fenómeno tradicionalmente deslegitimado en el marco de los sistemas democráticos, haciendo referencia en primer lugar a su perpetuada existencia, a sus posibles patologías y sobre todo reconociéndole cierta institucionalidad (funcionalidad) como medio de supervivencia.

A la hora de estudiar el clientelismo político también son pertinentes los estudios realizados por Javier Moreno Luzón (1995), quien analiza los lazos clientelares en la España contemporánea partiendo del régimen liberal de la restauración monárquica hasta la actualidad. Moreno Luzón, al igual que Corzo, hace referencia al caciquisimo y otros fenónemos emparentados con el clientelismo. No obstante, el autor reconoce que "la política de clientelas se sirve de prácticas corruptas, aunque estas no deben ser confundidas con ellas, ya que esta política incluye también otras estrategias" (Moreno, 1995: 194). Este autor a su vez vincula el clientelismo con el patronazgo, la clase social, la violencia, las estrategias de poder y lo relaciona con la cultura y la conflictividad política, el localismo, el Estado y la modernización de la política.

En Latinoamérica un referente obligado lo constituyen los estudios etnográficos adelantados por el sociólogo Javier Auyero $(1997,2002)$ quien suele situar la perspectiva de análisis en los puntos de vista de "quienes reciben favores", es decir, los clientes. Sus trabajos ponen el énfasis en la distribución de bienes a cambio de asistencia y participación en los actos públicos organizados por el partido político justicialista de Buenos Aires. Auyero, no solo ofrece pistas conceptuales para entender este fenónemo, sino que proporciona claves metodológicas de gran valor para recaudar y sistematizar la información.

Otro trabajo importante sobre clientelismo político es el realizado por el investigador Pablo Torres en la municipalidad de "El Pampero", en el Cono Urbano Bonarense. En su investigación, Torres se pregunta por las formas de estructuración y funcionamiento de las relaciones clientelares vinculadas a la implementación de prácticas políticas asistenciales por parte de la Dirección de Bienestar Social de la municipalidad de "El Pampero", durante el período 10/12/1983 a 10/12/199 y a partir de una perspectiva relacional, incorpora en su trabajo a las instancias estructurales donde los agentes actúan (el Estado, 
el municipio, los programas sociales, los partidos políticos y los medios de comunicación) y articula conceptos teóricos con el análisis detallado y riguroso de la información.

De igual forma, la tesis de grado doctoral "De proveedores a clientes. El dilema en el que las redes clientelares colocan a la gestión social. El caso del municipio de La Plata", realizada por la investigadora Fabiola Cárcar (2007) describe y explica cómo funcionan las redes clientelares en la implementación concreta de una política social en la ciudad de La Plata. La tesis toma como objeto de estudio a los gestores del programa de comedores comunitarios de esta ciudad, entre 1995 y 2005, y analiza quiénes son los actores intervinientes y cuáles son los bienes y mecanismos objetos del intercambio, a partir de la teoría del clientelismo político (Cárcar, 2007:2). Esta investigación no solo es un referente formal a la hora estructurar el trabajo de campo que se hará en Cartagena, sino que aporta una nueva mirada que amplía la perspectiva hacia los bienes y servicios que pueden intercambiarse en las cadenas clientelares. Para los fines de esta investigación, también es pertinente tener en cuenta los textos producidos por la investigadora alemana Bárbara Schröter, quien extiende el concepto de clientelismo a partidos políticos clientelares, su forma de organización y sus estrategias para ganar elecciones.

Así mismo, en el artículo "Cómo los ciudadanos mexicanos perciben el clientelismo electoral" publicado por Andreas Schedler, doctor en Ciencias Políticas y profesor investigador de la División de Estudios Políticos del Centro de Investigación y Docencias Económicas (CIDE) en la Revista Mexicana de Sociología, número 66, examina la economía moral del clientelismo electoral (la compra de votos) en México y a partir de entrevistas cualitativas realizadas a fines de 2000 en áreas rurales, explora la manera en que los ciudadanos y las ciudadanas evalúan el intercambio de votos por bienes. Estas entrevistas forman parte de un estudio más amplio sobre manipulación electoral llevado a cabo por la Facultad Latinoamericana de Ciencias Sociales (Flacso), sede México, y financiado por el Instituto Federal Electoral (IFE). El texto ofrece pistas sobre el resurgimiento del clientelismo electoral en México y sobre la economía moral de la compraventa de votos. Posteriormente revisa las percepciones y evaluaciones de los votantes respecto a algunos aspectos medulares del clientelismo electoral: sus ideas acerca de las obligaciones sociales que surgen a partir de la recepción unilateral de favores materiales; sus estrategias para evitar o redefinir tales obligaciones de reciprocidad; sus percepciones acerca de la disposición de sus conciudadanos a participar en la venta de votos; sus 
propias actitudes normativas hacia la explotación comercial del derecho al voto; su apreciación crítica de las prácticas clientelistas y, por último, su exigencia de aplicar políticas públicas no particularistas (Schedler, 2004: 59).

Poco se ha investigado en Colombia sobre este tema, no obstante el artículo "Lo patológico y lo democrático del clientelismo", publicado en la revista Nueva sociedad No.74, septiembre-octubre de 1984 por Hernando Gómez Buendía, economista y sociólogo colombiano, doctor en Derecho y en Filosofía, pone de manifiesto la incidencia sobre el proceso electoral y sobre la administración pública que históricamente han tenido las prácticas clientelares en Colombia. Sin embargo, el autor reconoce que no existen argumentos irreductibles ni evidencia empírica como para establecer el grado de precisión de esta sospecha. Para este autor es innegable la universalidad del clientelismo - y el clientelismo político - en el tiempo y en el espacio; lo cual no equivale a afirmar que en todas partes asuma las modalidades o alcance el nivel aparentemente "hegemónico" que reviste en Colombia. La crítica simplista y sobre generalizada del clientelismo corre el riesgo de ignorar - y de ignorar interesadamente, para distraerlo - el trasfondo "estructural" de la política colombiana, donde las clases sociales, las fracciones de clase y las organizaciones de interés, en su calidad de grupos categoriales, han tenido y tienen por supuesto una profunda, aunque compleja, gravitación sobre el reclutamiento de la administración pública, la prestación de servicios estatales y la movilización de apoyo electoral (Gómez: 1984: 91-95).

A manera de hipótesis interpretativa, este investigador plantea que "la cultura colombiana" podría ser más clientelista que la de otros países iberoamericanos debido a que existe una clase alta relativamente homogénea que ha logrado mantener sin interrupciones abruptas o profundas su hegemonía cultural y política a través del control personalizado que significa la pirámide de lealtades verticales. Las "antiélites son cooptadas", en la expresión de Fals Borda (1968: 186-189). Y va más lejos cuando afirma que la práctica se institucionaliza en cada esfera de la vida social, según la cual en Colombia no existen derechos sino favores, y no existen deberes sino lealtades (Gómez: 1984: 91-95).

De igual forma, resulta pertinente tener en cuenta un estudio realizado por Ronald P. Archer Ph.D. en political science from the University of California at Berkeley cuyo principal argumento es que la transición en el tipo de clientelismo en Colombia, de uno tradicional a uno de intermediarios, ha tenido un profundo impacto sobre la capacidad de las elites políticas colombianas para enfrentar 
problemas cada vez más serios de conflicto social y de violencia política. El trabajo concluye que el desgaste de las fuentes tradicionales de autoridad y legitimidad y su sustitución por un clientelismo de intermediarios basado en la influencia personal, han llevado a un inmovilismo político y han constreñido las acciones de quienes podrían hacer reformas y crear nuevas instituciones.

El recorrido que hasta aquí se presenta, apenas constituye un breve estado del arte que será refinado de manera paralela a los avances en el trabajo de campo que implica una investigación sobre clientelismo político y comunicación política en Cartagena.

\section{LA PREGUNTA POR EL TEMA CLIENTELAR EN CARTAGENA}

De manera particular esta investigación se pregunta por las relaciones entre el sistema clientelar institucionalizado en Cartagena de Indias y las premisas de campaña que han entrado en tensión en los debates electorales de Alcaldía de la ciudad durante el presente siglo, lo cual, a manera de problema se expresa de la siguiente forma: ¿En qué consiste la mediación entre el sistema clientelar puesto en práctica en Cartagena de Indias y las distintas campañas políticas durante los procesos electorales del siglo XXI a la Alcaldía Distrital de esta ciudad?.

Esta pregunta, naturalmente, se formula en el marco de un sistema democrático, o lo que en palabras de Robert Dahl se conoce como poliarquía, un régimen con alto grado de apertura y debate político que mínimamente debe contener estos siete aspectos:

- La libertad de asociación y organización.

- La libertad de pensamiento y expresión.

- El derecho de sufragio activo y pasivo.

- El derecho a competir por el apoyo electoral.

- Fuentes alternativas de información accesibles.

- Elecciones periódicas libres y justas, que produzcan mandatos limitados

- Existencia de instituciones que controlen y hagan depender las políticas gubernamentales del voto y de otras expresiones de preferencias.

En cada uno de los aspectos desarrollados por Dahl (1989: 100-104), están imbricados los conceptos más importantes alrededor del cual gravita el presente trabajo: Comunicación política, sistema clientelar, elecciones, ciudadanía y democracia.

Palobra No. 13. Agosto de 2013 
Muñoz Alonso (1989) advierte que las campañas político electorales constituyen uno de los procesos más importantes en una sociedad democrática y al propiciar un intercambio de sentidos en virtud de la toma de decisiones, generan un proceso de comunicación y deliberación pública. El problema planteado en esta investigación se adscribe justamente en la dimensión comunicación política, y establece un vínculo entre los diferentes actores que confluyen en ella: ciudadanía, partidos políticos, candidatos, estado y medios de comunicación (Bonilla, 2003).

Javier del Rey Morató (1996) en "¿De qué hablamos cuando hablamos de comunicación política?" explica que Comunicación y Política constituyen dos amplias y complejas esferas, unidas en el análisis de la realidad social y agrega que un análisis adecuado de estas dos instancias debe comprender las relaciones que se dan entre las estructuras institucionales, los actores y el contexto cultural en el que los medios de comunicación generan nuevas formas y nuevos contenidos políticos. De manera que, desentramar las relaciones que subyacen entre los actores (propios de la comunicación política) y las prácticas clientelares en la ciudad, supone seleccionar determinados objetos de referencia que ofrezcan posibilidades de análisis. En razón a ello, por ahora se plantea adelantar el estudio a partir de los procesos electorales de Alcaldía en Cartagena de Indias durante el siglo XXI (2000-2011).

Con el ánimo de ofrecer una mirada al terreno que ocupa la discusión en la ciudad, vale la pena remitirse a Barbero (2001) en su ponencia "Cambios en el tejido cultural y massmediación de la política", que hace parte del compilado "Comunicación y Política viejos conflictos, nuevos desafíos", editado por la Universidad Javeriana de Colombia, en la cual explica que la ciudad es hoy "el lugar propio de reinvención de la democracia. Pues cualquier ciudad grande, incluso mediana, es hoy ingobernable únicamente con los saberes de expertos, esto es, sin una política que se haga cargo de la experiencia de los ciudadanos" (Barbero, 2001: 19) y es justo este uno de los puntos en donde empiezan a converger el mundo de las prácticas clientelares, de la vida de la gente y sus preocupaciones, con el mundo de la producción de sentidos que generan los procesos comunicativos en virtud del acontecer que atraviesa la realidad social de Cartagena, caracterizada por presentar una dinámica de exclusión socioracial que se traduce en desigualdades, desventajas e inequidades, que afectan mayoritariamente a la población afrodescendiente y otros grupos minoritarios y que, de acuerdo con el Observatorio de Derechos Sociales, Odesdo, tiene el 75\% de su población viviendo en la exclusión, la 
miseria, la discriminación racial y el "apartheid" socio-espacial, abandonado de la acción estatal.

Tal como lo explica el investigador Libardo Sarmiento Anzola (2010), la comprensión de la situación de Cartagena pasa por la compresión de las relaciones con los conquistadores y luego colonizadores, y con las relaciones de poder y los significados que desde allí comenzaron a tejerse. "En su complejidad histórica, atravesada por el conflicto de clases que producen y reproducen esta específica formación social y sus relaciones socioeconómicas y políticas que se fundamentan en la expoliación, la opresión y la explotación que alimenta la voracidad de la acumulación capitalista, de propios y extranjeros, habría que rastrear las claves para entender la configuración actual de la crisis social que vive la ciudad".

Sarmiento agrega que para las comunidades afrocolombianas y populares, el desarrollismo de las élites cartageneras siempre significa violencia, despojo, destierro, segregación y exclusión. 'Uno, entre miles de ejemplos, recuerda este trágico destino: Chambacú. La novela costumbrista de Manuel Zapata Olivella relata cómo la plutocracia de la "Heroica" convirtió los ranchos de cartón y paja, donde habitaban "los negros", en "tierra de muerte", para después transformarla en uno de los principales "polos de desarrollo y valorización" de Cartagena. Este hecho constituye un penoso símbolo de la más cruda historia del racismo en Colombia'.

Según los datos del Departamento Nacional de Planeación (DNP), la pobreza en Cartagena pasó de 35,8 por ciento en 2008 a 36 por ciento en 2009. En la extrema pobreza se mantienen nueve de cada 100 cartageneros. No obstante, en los niveles 1,2 y 3 del Sisben, que el sistema asimila a población en condiciones de pobreza, se encuentra el 90,5 por ciento de la población.

La pobreza, tan extendida en Cartagena, una ciudad portuaria con un amplio desarrollo turístico e industrial, de acuerdo con Sarmiento, obedece a una economía de enclave que no genera empleo digno. Durante 2010, la tasa de desempleo fue de 12,5 por ciento, por encima del promedio de las 13

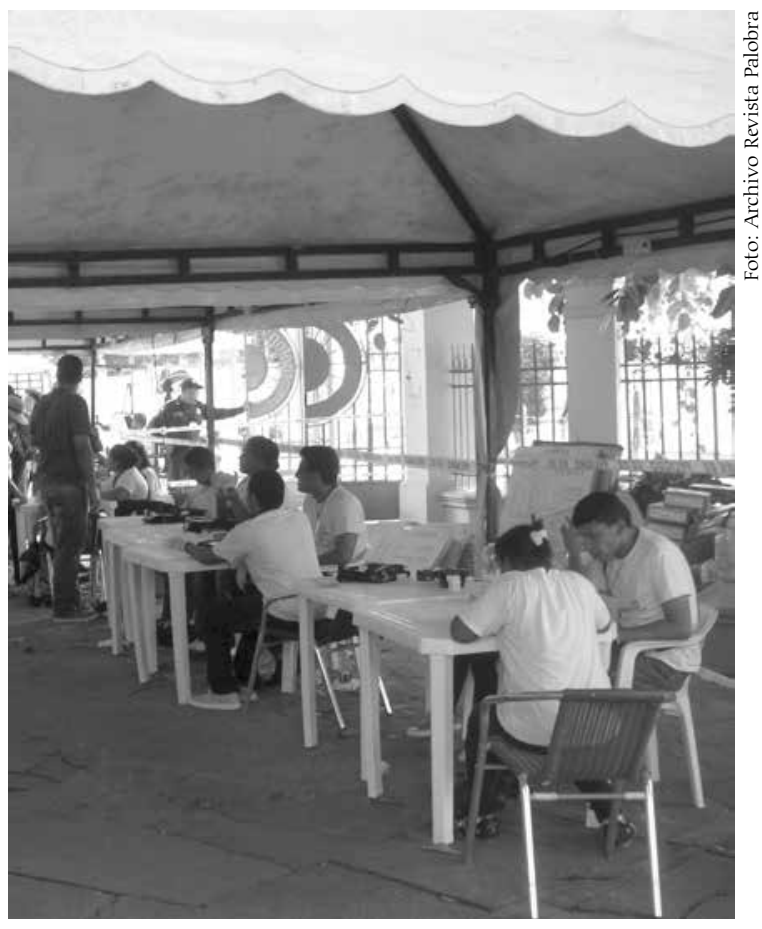

Jornadas electorales 2013. 
principales ciudades del país. El empleo informal afectó al 60,5 por ciento de los trabajadores, esto es, en condiciones precarias, inestables y sin seguridad social. En una economía de enclave, añade Sarmiento, las empresas carecen de vinculaciones significativas con los circuitos de la economía local. No hay un proceso de difusión tecnológica ni de entrenamiento o capacitación de la mano de obra nativa; tampoco una articulación con actividades complementarias locales, como el sistema educativo, las políticas sociales o el desarrollo urbanístico.

Según una investigación citada por Sarmiento, "en las tres últimas décadas Cartagena ha sido una de las ciudades colombianas con mayor crecimiento económico y demográfico. Sin embargo, la repartición de esa prosperidad ha sido muy desigual. Cartagena es una ciudad con gran polarización en los ingresos y las oportunidades sociales, lo cual tiene una clara manifestación en el espacio físico: los pobres están localizados en determinados sitios, y los más altos ingresos están en otros lugares. Además, hay un componente étnico en esa polarización. Los más pobres, que además se ubican en los sitios menos atractivos, son mayoritariamente afrodescendientes".

De otra parte, argumenta Sarmiento, "el manejo de las finanzas públicas no promueve la justicia, la equidad ni la inclusión. Los ricos no pagan impuestos y los programas sociales son de corte asistencialista. El déficit fiscal de Cartagena es de carácter estructural, lo que refleja: i) la clase dirigente no es proclive a afectar la desigual distribución del ingreso a través de los mecanismos fiscales que dispone la administración local, ii) el rápido enriquecimiento de la ciudad durante las últimas décadas ha beneficiado principalmente a los ricos, en una tendencia constante de concentración de la riqueza, sin que se refleje en un fortalecimiento de las finanzas públicas, iii) el financiamiento del déficit de la ciudad mediante empréstitos beneficia al sector financiero, a la vez que les quita recursos a las vigencias futuras y genera dependencia política de la ciudad respecto a los intereses de los banqueros, iv) la ciudad, en la actual estructura presupuestaria, no cuenta con procedimientos incluyentes (presupuestos participativos) ni con los recursos financieros sostenibles para adelantar una política pública social que garantice la inclusión, la universalidad de los Derechos Humanos y el ejercicio pleno de la ciudadanía de los cartageneros". (Sarmiento, 2010)

Ante un contexto político y económico tan adverso como el de Cartagena y teniendo en cuenta la incapacidad sistemática de sus gobiernos para garantizar 
las condiciones mínimas de calidad de vida a la gente, un amplio sector de la población obtiene beneficios reales y a veces inmediatos de su relación con los candidatos y grupos políticos que se disputan el poder. De modo que, tal como explica Ancízar Narváez Montoya (2001: 82) "la dinámica clientelista no está en cuestión todavía para la gente de los barrios marginados, los pequeños municipios y las zonas aisladas". El fenómeno del clientelismo, o lo que Auyero (2001) llama la "política de los pobres", es algo que suelen poner en discusión los académicos pero que para una parte importante de la gente, sigue siendo el principal mecanismo para acceder a los recursos del estado y resolver sus problemas de vida. Más allá del dilema ético que estas prácticas podrían plantear, Narváez Montoya recalca (2001: 83) que se trata de un hecho político y que todos los circuitos a través de los cuales circulan la política no mediática (y también mediática) merecen ser investigados desde la comunicación.

\section{PERTINENCIA ACADÉMICA Y SOCIAL}

Investigar la relación entre el sistema clientelar cartagenero y las promesas de campaña que circularon en los procesos electorales de Alcaldía en este siglo, ayudará a robustecer la producción del conocimiento en este campo y, dado que el clientelismo es un sistema de mediación de intereses políticos e incide de manera profunda en todo tipo de mediaciones sociales, está estrechamente ligado a la línea "Mediaciones y formaciones sociales" que hace parte del grupo "Cine, historia y modernidad", del programa de Comunicación Social de la Universidad de Cartagena.

Una investigación de esta naturaleza también está emparentada con la línea investigación Comunicación, Sociedad y Cultura del Doctorado en Comunicación de la Universidad Nacional de la Plata, línea que "abarca el estudio de las mediaciones, el estudio de la recepción y el consumo, la relación de la vida cotidiana con las tecnologías, las prácticas sociales y culturales, la constitución de las ciudades, vida urbana y rural, producción de sentidos sociales en relación con otras disciplinas (historia, antropología, ciencias de la educación, sociología, psicoanálisis, etc.), los grupos sociales diferenciados, las minorías, procesos microsociales y macrosociales, la globalización, la mundialización, identidades reestructuradas por dichos fenómenos y fronteras culturales, etc" (Ámbitos temáticos del doctorado).

En cuanto al tema particular del clientelismo político, conviene advertir que es posible sospechar muchas cosas desde el sentido común y caer en la tentación 
de los prejuicios, como bien lo señala Tenti (2002), cuando asegura que son escasos los análisis empíricos y teóricos fundamentados alrededor de este tema y que abunda la especulación ( y la escasez empírica), de modo que, investigar las prácticas clientelares y ponerlas en relación con las campañas electorales de la ciudad, resulta pertinente en virtud del devenir histórico que lo soporta y a partir de las pistas tanto conceptuales como prácticas que podría aportar en el ejercicio de comprender el juego político que libran las élites políticas de Cartagena y la sociedad civil con las diferentes complejidades que median en sus intercambios, incluyendo a los medios de comunicación como instancias para la deliberación y el debate público y como agentes (re) productores de sentido.

Naturalmente los intercambios a los que se hace alusión cuando se habla de clientelismo, no ocurren de manera pavloviana: estímulo-respuesta (o lo que en clave clientelar podría equipararse a "favores por votos") sino que existe un entramado de mediaciones y construcciones sociales, de las que se ocupará este estudio, en un contexto muy particular: La Cartagena electoral del siglo XXI.

Teniendo en cuenta el carácter vinculante que posibilita la comunicación al marco general de las ciencias sociales, es posible creer que una investigación como la que aquí se plantea ayudará a comprender las relaciones suscitadas entre la perpetuación del sistema clientelar puesto en práctica en la ciudad y las premisas o promesas de campaña postuladas por las diferentes campañas políticas durante los procesos electorales de Alcaldía en el siglo XXI.

En este punto también conviene advertir que pese a que hay suficientes evidencias empíricas de lo que se podría reconocer como parte de ese relacionamiento político en el que se intercambian favores, prebendas o servicios por votos, en la ciudad no existe un análisis en profundidad que sistematice estas evidencias y se esfuerce por explicarlas poniéndolas en relación con otros factores que intervienen en el ámbito de la comunicación y la democracia, de modo que la investigación intentará llenar este vacío y aportará nuevos datos de referencia para ampliar la reflexión en torno a un fenómeno existente en todos los sistemas políticos conocidos (Graziano, 1983) especialmente en los democráticos (Auyero, 1996), pero que se resignifica en cada contexto y que adquiere sus propias características en una ciudad como Cartagena, atravesada por la pobreza y la desigualdad.. 


\section{LA CUESTIÓN RELACIONAL DEL CLIENTELISMO}

En el capítulo "Entender el clientelismo y profundizar la democracia", escrito por Emilio Tenti Fanfani como comentario al estudio "Votos, chapas y fideos, clientelismo político y ayuda social", realizado en Argentina por el investigador Pablo Torres (2002: 4), Tenti destaca la mirada relacional de la mencionada investigación al reconocer el clientelismo no como una substancia sino como una cualidad de una relación entre agentes o lo que en términos de Weber haría referencia a una relación entre un soberano (jefe político, caudillo o líder), un cuadro administrativo (los mediadores) y los dominados (los "clientes"). Pero la virtud del trabajo de Torres, de acuerdo con Tenti, está en que este autor incorpora a las instancias estructurales donde actúan dichos agentes: El Estado, el municipio, los programas sociales, los partidos políticos y los medios de comunicación, entre otros, instancias que concuerdan con las reconocidas por Bonilla (2003) como objeto de estudio de la comunicación política.

De tal manera que, el esquema analítico que aquí se propone no solo tendrá en cuenta los actores intervinientes en la trama clientelar -patrón/mediador/ cliente (Auyero, 1996) sino que incorporará otras instancias de poder como son los medios de comunicación (en su tarea de construir opinión pública y ofrecer elementos de juicio para la toma de decisiones), los partidos políticos (como organizadores de las ideas de quienes compiten por el poder) y en un sentido más amplio, las irrigaciones del modelo en donde operan los procesos políticos, económicos y sociales de la ciudad.

Pero, si se quiere hacer foco en el concepto de clientelismo, es pertinente recordar que históricamente el término ha sido utilizado de diferentes maneras y con diferentes propósitos. Corzo (2002: 66-68) explica que etimológicamente el término deriva de la raíz latina "cliens", la cual expresa tres verbos posibles: cluere, clinere y colere. Los dos primeros significan, respectivamente, "estar atento a" y "apoyarse en", con lo que la relación se define bajo una estructura social en la que existe dependencia. Colere, en cambio, significa "habitar con" con lo que la relación se produce en términos de aparente igualdad. Solo antiguamente colere se asocia con cliens porque luego evoluciona hacia colens o colonus, origen de la palabra colono en el medio rural, adaptándose así a una relación de mayor dependencia económica que cuando se trataba de "habitar con". 
Es en el ámbito rural y feudal donde se origina lo que se conoce como patronazgo, con el que se denominan también las relaciones clientelares. Este término deriva del español patrón, persona con poder, estatus, autoridad e influencia sobre otra persona de menor poder o "cliente", el cual recurre a él por ayuda o protección (Hall, 1977). Puede estar representado en la figura del empleador, un mecenas, o incluso un santo protector. Esta mirada coincide con la del investigador Javier Moreno Luzón (1995: 193) quien argumenta que el término que, en general, designaba de forma aproximada la política de clientelas a principios del siglo XX era el caciquismo, una práctica asociada a la manipulación electoral por parte del gobierno, que incluía el ejercicio del patronazgo político por parte de jefes y caciques, pero también otros métodos.

Otros autores como Boissevain (1985) también relacionan el clientelismo con el patronazgo, es decir con "el complejo de relaciones entre aquellos que usan su influencia, posición social, o algún otro atributo, para asistir y proteger a otros que necesitan su ayuda y protección" y otros (Lemarchand y Legg) ponen el énfasis en las transacciones que se realizan entre una parte y otra. "Se trata de una relación más o menos personalizada, afectiva y recíproca entre agentes, o grupos de agentes, dotados de recursos desiguales, y que comprende transacciones mutuamente ventajosas que tienen ramificaciones políticas más allá de la esfera inmediata de la relación diádica" (Lemarchand y Legg, 1972: 151 ss).

O’Donell (1997), reconoce que el clientelismo, en términos amplios no reducidos al político, es un patrón de comportamiento que, junto a otros particularismos, está fuertemente arraigado en las sociedades de los países subdesarrollados y es considerado una institución, en el sentido de constituir un patrón regularizado de interacción que es conocido, practicado y aceptado (si bien no necesariamente aprobado) por actores que tienen la expectativa de seguir interactuando bajo las reglas sancionadas y sostenidas por ese patrón. La mirada de O'Donell es ampliada por Torres, quien agrega que el clientelismo "es una institución frecuente en las democracias en los países subdesarrollados, no universalista, que se presenta como una relación de intercambio entre personas pero que es- en realidad- una relación de dominación, de la que participan ciertos individuos (patrones) que prestan determinados servicios, bienes o favores a otros (clientes) que los retribuyen con fidelidad, asistencia, servicios personales, prestigio, apoyo político y electoral. Entre ambos (patronos y clientes) puede encontrarse a los llamados mediadores que ejercen 
una intermediación de suma importancia para la reproducción de la relación clientelar." (Torres, 2002:26-27).

Auyero (1996: 35) por su parte, y citando a Scott y Kervvliet, explica que "el clientelismo perdura como una institución extremadamente influyente y (la más de las veces) oculta, no destinada a desaparecer ni a permanecer en los márgenes de la sociedad, sea con la consolidación de regímenes democráticos, sea con el desarrollo económico". Y agrega que las relaciones clientelares pueden ser entendidas como "un intercambio personalizado de favores bienes y servicios por apoyo político entre masas y élites", mirada que coincide con la de Scott (1977) para quien el clientelismo es "una forma especial de relación de intercambio entre individuos, uno relativamente más poderosos que el otro, lo cual sirve para las redes y alianzas" y con la postura de Farinetti (1998:86) quien define el clientelismo político como "una relación de dominación que se presenta como relación de intercambio".

Desde otro ángulo, Luigi Graziano se refiere al "síndrome clientelista" como "un fenómeno universal, a despecho de quienes han intentado reducirlo al ámbito de las sociedades tradicionales" (Graziano, 1983: 425-432), mientras que Caciagli (1996) lo de fine como "Relación diádica en virtud de la cual una persona de estatus más elevado, el patrono, utiliza su influencia y sus recursos para facilitar protección y beneficios a otra persona de estatus inferior, el cliente, que ofrece servicios y/o apoyo. Es por lo tanto una relación de poder personalizada que implica un intercambio social reciproco y mutuamente beneficioso. Si la relación simple es entre dos personas, las más complejas son entre roles. La red clientelista es un conjunto de roles, estructurada en cadenas piramidales".

Pero en la mitad de todas estas posturas existe una lectura más negociada que argumenta que el clientelismo es la "consecuencia de una relación personal de intercambio, en el ámbito de la política, que se establece de forma voluntaria y legítima, dentro de la legalidad, entre los que pueden ocupar u ocupan cualquier cargo público y los que desean acceder a unos servicios o recursos públicos a los que es más difícil llegar, que no imposible, de no ser por este vínculo o relación (Corzo Fernández, 2002:66).

Sin que todavía sea un tema agotado, todas las definiciones aquí planteadas a manera de síntesis, reflejan las características básicas de una relación clientelar: 1) es desigual, ya que el intercambio se origina y refleja en la disparidad de riqueza, poder y estatus relativos; 2) es personalizada, aunque la relación 
patrón-cliente pueda estar mediada por terceras personas (mediadores o líderes barriales), el vínculo con ellas es personalizado; 3) implica un intercambio de bienes y servicios concretos, con lo que hay reciprocidad; y 4) es informal, difusa y simbólica (Kaufman, 1974; Scott, 1985). Estos cuatro aspectos encierran la complejidad de las relaciones clientelares y la pertinencia de su estudio desde una perspectiva comprensiva.

De otra parte y con el ánimo de despejar cualquier prejuicio moralista y aclarar ciertos datos que se prestan a confusión, la autora Susana Corso Fernández (2002) también explica que si bien la corrupción ha sido un término estrechamente relacionado con el clientelismo político, porque en ambos casos se produce un intercambio, esta última implica una situación que procede desde la autoridad y se dirige a actores que no lo son para incrementar el poder de dicha autoridad (corrupción ascendente) o viceversa, es decir, de los actores hacia la autoridad (corrupción descendente) para incrementar el patrimonio de los mismos (Belligni, S., 1987: 61-68, citado por Corso, 2001). En ambos casos se superan los límites de la legalidad para obtener beneficios extraposicionales, lo que en términos jurídicos deviene en soborno y extorsión.

Al respecto Della Porta e Ives Meny (citados por Corzo 2001) puntualizan que en la corrupción el intercambio que se produce está basado en intercambiar decisiones por dinero, mientras que en el clientelismo, de acuerdo con Graziano median la confianza y la lealtad, un aspecto que también es reconocido por Auyero (1996) en lo que él llama el "favor fundacional" o el punto de partida para el establecimiento de la relación clientelar.

En la corrupción el intercambio se produce en los márgenes de la ilegalidad, la ilegitimidad y la clandestinidad y es una práctica que genera inquietud en la sociedad civil ya que no encaja en los patrones sociales que definen las conductas aceptadas para el desarrollo de la actividad pública (Jiménez de Parga, 1997, citado por Corzo 2001), a diferencia del clientelismo, en donde no se intercambia un contenido al que pueda atribuírsele un precio estándar, pues la valoración parte desde la subjetividad de lo que la otra parte está dispuesta a intercambiar. En la corrupción hay plena conciencia de la ilegalidad del intercambio, mientras que en el clientelismo no hay una conciencia absoluta de que se esté realizando algo que se tenga que esconder (Corzo, 2001). 
Las diferentes posturas presentadas de manera muy resumida aportan pistas para entender la complejidad del asunto y la pertinencia de su estudio en diferentes contextos, de modo que, el clientelismo, como sistema institucionalizado desde la informalidad, como ya se dijo, merece ser estudiado a partir de una perspectiva comprensiva más que objetivista o descriptiva, porque -y parafraseando a Bourdieu- el peligro del objetivismo es ese forzar los cierres, y caer en el juego de las lecturas hegemónicas.

\section{MEDIACIONES Y CAMPAÑAS POLÍTICAS}

Dado que esta investigación comprenderá un recorrido por las diferentes premisas discursivas (promesas de campaña) que pusieron en juego los candidatos ganadores de las elecciones de Alcaldía en Cartagena durante el siglo XXI y su relación con el sistema clientelar, resultará inevitable indagar por el tratamiento periodístico que los diferentes medios de comunicación de Cartagena dieron a los candidatos que se disputaron la alcaldía en los diferentes períodos electorales a estudiar. En este punto será especialmente útil el concepto de mediaciones.

Martín-Barbero (1987: 203) ha dicho que la mediación es una instancia cultural desde la cual los significados y sentidos son producidos y apropiados por la audiencia; Orozco (1992) complementa la idea de Martín-Barbero y entiende la mediación como el proceso de recepción donde se crean y recrean significados y sentidos desde la interacción de la audiencia con el medio y con las otras instancias sociales. "Estructuran el proceso de aprendizaje e incluyen intervenciones de los agentes sociales e instituciones en el proceso de recepción".

Por su parte el teórico español Manuel Martín Serrano (1985) en un primer momento se refiere al término para hacer referencia a la relación entre redundancia y entropía. Serrano equipara el acontecer con la dimensión entrópica y, establece una relación con el prever y el creer. La relación acontecer - prever, da lugar a la forma de los mensajes o mediaciones estructurales. La relación acontecer - creer da lugar a los contenidos de los mensajes o mediaciones cognitivas. Ambas relaciones son determinadas por Serrano como tensiones donde ocurre la mediación.

De este modo, las mediaciones se constituyen en decisiones que, tanto el emisor como el receptor, se ven abocados a tomar frente a los mensajes con miras a construir su significado ya sea en su producción como en su 
consumo, lo cual se convierte en la evidencia concreta frente al fenómeno de la interpelación provocado por los candidatos a partir de sus discursos y programas de gobierno, las piezas publicitarias que utilizaron en sus campañas y la agenda temática postulada por los medios en virtud de sus propias rutinas de producción.

En términos prácticos, la mediación estructural -dice Serrano- opera sobre los formatos y la cognitiva sobre los relatos. La confluencia de estas dos dimensiones resultará pertinente al momento de hacer la tarea de revisión de contenidos para comprender el vínculo entre lo discursivo (premisas de campaña, programas de gobierno, slogan publicitarios, datos reiterativos) y lo ritual (medio empleado para difundir las ideas de campaña, lugar ocupado dentro de los espacios de cada medio, piezas publicitarias, etc) y yendo más lejos las implicaciones que en clave clientelar tuvieron dichas mediaciones (cómo negociar el discurso que circula por los medios en el ámbito barrial), especialmente en tiempos de campañas electorales.

De acuerdo con Muñoz Alonso (1989) una campaña electoral es o puede ser "una ocasión excepcional en la que se intensifica y se hace más patente el múltiple diálogo democrático. Es un momento especial en el permanente diálogo entre gobernantes y gobernados; pero, por otra parte, es la ocasión en que se presentan ante la opinión pública las nuevas propuestas de los aspirantes a gobernar", de ahí que esta investigación centre su objeto de estudio en los procesos electorales de la ciudad, porque se reconoce en ellos un período especial en el que concurren diversas ofertas y demandas, mediaciones e intercambios que, en definitiva, llevan al elector (ciudadanos) a tomar decisiones a partir de las diversas opciones ofertadas y la correspondencia de estas con sus propias demandas.

Según Serrano (1985), la participación de los medios de comunicación masiva en la elaboración de las agendas mediáticas inicia cuando la institución mediadora (el medio) selecciona determinados aconteceres para hacerlos públicos y agrega que la tarea específicamente comunicativa comienza cuando los emisores eligen, en el marco de ese acontecer público, determinados objetos de referencia. Los datos deben expresarse en un soporte material (el periódico, la radio, la pantalla de televisión, etc).

Otro concepto importante en el marco de la teoría de la mediación social postulada por Serrano tiene que ver con el Acontecer Público. El concepto 
se refiere a determinados emergentes que ocurren en la realidad social y que agregamos, se agudizan en tiempos de elecciones por las tensiones propias que se generan en la disputa por el poder. Lo emergente constituye el acontecer público donde los profesionales de los medios de comunicación, operacionalizan las mediaciones. En otros términos, los periodistas seleccionan los emergentes que hacen participar al medio de comunicación en el acontecer público. Es así como la "tarea mitificadora" llevada a cabo por el medio de comunicación se da en la tensión entre acontecer//creer. Y, la "tarea ritualizadora" se da en la tensión entre acontecer//prever. Así mismo el objeto sobre el que se llevan a cabo las tareas de mitificación y ritualización es el producto comunicativo; el cual desde el punto de vista de las representaciones consiste en un repertorio de datos de referencia relativos al acontecer público a propósito del que se comunica: los presencias de los candidatos en la ciudad, sus promesas, sus apuestas, sus posturas frente a los temas de la agenda, frente a la realidad social de la ciudad, sus propuestas de gobierno.

El anterior concepto sirve para llevar a cabo la denominada técnica de análisis de contenido a la que Serrano llama "métodos de análisis de las representaciones del relato" y también para aplicar las técnicas de "análisis formal" las que el mencionado autor denomina "métodos de análisis material" de las expresiones comunicativas y los productos comunicativos. De manera que el llamado acontecer público se caracteriza de acuerdo con la teoría de las mediaciones, por los mitos y ritos que subyacen en el producto comunicacional que circulan en la sociedad. Para el propósito de esta investigación el concepto de producción del acontecer público facilitará la fase de interpretación sobre la relación entre lo que acontece (las prácticas clientelares de la ciudad y su relación con los procesos electorales), las mediaciones realizadas entre los diferentes actores que intervienen y las diferentes promesas de campaña que se expresan tanto en los discursos públicos, como en las piezas publicitarias.

Eliseo Verón (1992) por su parte, explica que la mediatización opera a través de diversos mecanismos según los sectores de la práctica social que interese y produce, en cada sector, distintas consecuencias. De ahí, una vez más, la pertinencia de establecer ciertas delimitaciones que permitan hacer más productivos los resultados de esta investigación desde una perspectiva más comprensiva. 


\section{CAMPAÑAS ELECTORALES}

Para aproximarse al mundo de las campañas electorales, es pertinente acercarse a la literatura del marketing político. Desde allí es posible afirmar que una campaña no es simplemente un momento de reconocimiento social, ni de posicionamiento público, se trata de un proceso en el que "solo hay tiempo para conseguir votos y todas y cada una de las acciones deben apuntar a ello" (Santiago y Varela, 2006: 76). Otros autores entienden por campaña electoral el conjunto de actividades organizativas y comunicativas realizada por los candidatos y partidos que tienen como propósito captación de votos, definición que coincide con la de Santiago y Varela, quienes además explican la diferencia entre campaña política y campaña electoral.

Los autores citados aclaran que la campaña política alude a un trabajo político que va más allá del proceso electoral y que es realizado por un candidato o partido político. Forman parte de esta etapa la elaboración y difusión de proyectos, iniciativas, la generación de hechos políticos, las alianzas electorales y todo lo que resulte importante a la hora de encarar el debate electoral.

La campaña electoral, por su parte, es definida como "el proceso previo tres o cuatro meses antes- al día de la elección, en el cual el conjunto de los partidos y candidatos se vuelcan masivamente a la conquista del voto". (Santiago y Varela: 2006: 77;). Y aquí entran a jugar un papel importante ciertos elementos como la determinación de la estrategia, la cual se diseña varios meses antes del proceso electoral a partir de los sondeos de opinión, las encuestas, las investigaciones y el contexto político en el que la campaña se va a desarrollar y la posición que en él ocupan el candidato y el partido; de igual forma, resulta crucial en esta etapa la definición de los "blancos de comunicación", es decir de la manera de influir en el público (electores - clientes) aptos para votar de acuerdo al contexto. En este propósito es fundamental hacer un buen ejercicio de segmentación de la población y trazar una política de comunicación dirigida a los líderes de opinión, es decir, a aquellas personas capaces de influir en otras personas (receptores-electores) y persuadirlos.

"La campaña política es a la campaña electoral lo que la propaganda es a la publicidad. Como la publicidad es sslo una parte de la propaganda, la campaña electoral es sólo una parte de la campaña política de un candidato y de su partido". 


\section{APROXIMACIÓN METODOLÓGICA}

La organización espacio temporal propuesta (procesos electorales de alcaldía en el siglo XXI en Cartagena de Indias), ofrece un marco de referencia que permite fijar ciertos límites al objeto de estudio y a su vez encierra un período socioeconómico bastante significativo para la ciudad puesto que en estos años (2000-2011) empiezan a sentirse las consecuencias socioeconómicas y políticas que generó la apertura económica del país, iniciada en los 90’s. De manera que es posible anticipar desde ya que el cuerpo del trabajo incluirá una contextualización de la historia reciente de la ciudad que servirá como anclaje para entender su crisis social.

En términos metodológicos, un trabajo realizado en el marco del seminario "Investigación en Ciencias Sociales" del Doctorado en Comunicación de la Universidad Nacional de La Plata, dictado por el profesor Alfredo Alfonso, resultó muy pertinente en la tarea de encontrar pistas para abordar el tema de clientelismo político e identificar instrumentos que permitan aproximarse a los datos y a los posibles informantes o actores clave.

El trabajo consistió en contactar tres "punteros" (líderes) barriales, entrevistarlos, observar la manera en que se relacionan con la comunidad y escribir un análisis. La observación y la entrevista en profundidad fueron los instrumentos utilizados en el propósito de hacer un ejercicio que permitiera aproximarse al entramado de mediaciones suscitadas entre las prácticas clientelares de la Villa 31 de la ciudad de Buenos Aires (sitio escogido para hacer el trabajo de campo) y los actores que participan en el intercambio. El ejercicio dio como resultado un documento, en el que puede observarse cómo las prácticas clientelares en esta villa están atravesadas por la visión ideológica del peronismo y la idea de justicia social que encierra la oferta partidaria.

No se descartaría que la aplicación de técnicas similares a las puestas en prácticas durante el ejercicio (entrevista y observación) pueda funcionar en el trabajo de campo que habrá de realizarse en Cartagena de Indias para estudiar este fenómeno. No obstante, conviene reiterar la diferencia contextual que caracteriza a las dinámicas urbanas de aquí y de allá, para anticipar que el ejercicio no puede ser calcado ni aplicado de la misma manera.

La revisión bibliográfica previa al trabajo de campo mencionado también fue pertinente, ya que permitió el acercamiento a lecturas negociadas como 
las propuestas por los investigadores Rodrigo Zarazaga (2000), Javier Auyero y otros autores que han estudiado el fenómeno del clientelismo en Argentina. Seguirle la pista a sus hallazgos y a sus referencias bibliográficas siempre será una tarea pertinente para refinar las categorías conceptuales que inevitablemente entrarán a formar parte del marco teórico de la investigación.

Si bien la presente investigación no es una tesis de historia, el proyecto también se pregunta por el devenir histórico y cultural de las prácticas clientelares en la ciudad, de modo que la revisión bibliográfica seguramente llevará a referenciar la colonia, el caciquismo y todos los antecedentes que puedan aportar pistas para entender las configuraciones del sistema clientelar en Cartagena.

Volviendo a Torres, el abordaje de su investigación propone una metodología cualitativa que permite la aplicación de un muestreo intencional en donde interesa más lo que pueden decir las personas considerando que "cada individuo es un testimonio de la sociedad" y lejos de ser esencias fundantes, son primordialmente productores de las particulares configuraciones sociales que han desplegado en sus vidas (Saltalamacchia, 1997, citado por Torres 2002).

Torres a su vez expone algunos criterios de selección para la escogencia de la muestra de clientes de la red que entrarían a hacer parte de su investigación: Ser sistemáticos visitantes de la Dirección de Bienestar Social; y ser frecuentes receptores de la ayuda social.

Para el caso de la investigación sobre clientelismo en Cartagena, los criterios de selección de los informantes clave o entrevistados por ahora tendrían que reunir condiciones como: haber sido candidato en los procesos electorales a estudiar, jefe de campaña política, líder barrial o estratega publicitario.

Lo anterior plantea una pregunta, naturalmente: ¿Cuántas entrevistas serán necesarias para garantizar la validez de los resultados? En este tipo de investigaciones, emparentadas más con lo cualitativo que con lo cuantitativo, la elaboración de la muestra forma parte del proceso mismo de investigación, de modo que el criterio de la saturación, esto es: "el número óptimo de entrevistados será en el que se logra la saturación de la muestra, es decir, cuando al agregar nuevos entrevistados solo agregaría informaciones de interés secundario en relación al objeto de la investigación (Saltalamacchia, 
1997, citado por Torres 2002), será fundamental para estos fines. De manera que el trabajo de campo con los clientes, patrones, mediadores y/o líderes barriales, implicará también el diseño de una guía semi estructurada de preguntas que permita obtener mejores resultados.

Para orientar la investigación a su vez será pertinente acudir a dos perspectivas de análisis distintas, pero complementarias: las categorías propuestas por Eliseo Verón $(1996,1981,2001,2004)$ y por Jonathan Potter (1996) para analizar la manera en que se construyen los discursos y específicamente, las retóricas en que están anclados; y retomar los planteamientos del sociólogo Pierre Bourdieu $(1982,1995,1999,2000)$ para comprender el modo como inciden el campo y el hábitus de los hablantes en la manera en que estos construyen las retóricas de sus discursos.

La articulación de estas coordenadas se hará con un doble propósito. En primera instancia refinar método, procedimientos, categorías de análisis, interpretación y formulación teórica. En segunda instancia para instalarse en el discurso de las investigaciones sobre la mediación de los medios y su relación con la dimensión política en una sociedad y, de esta forma, aportar resultados que sigan lo expuesto en el núcleo de investigación que relaciona la comunicación con la cultura y la política.

Por otro lado, al ser la imagen un componente fundamental de la cultura, de la vida social y de la política, estudiarla deviene en reflexionar sobre cómo se construye socialmente el sentido en ciertos procesos de comunicación visual, como las piezas publicitarias que ponen en competencia los candidatos en cada proceso electoral. La imagen no solo se puede entender como un sistema complejo cargado de significación, si no que también constituye una estrategia política y social, un elemento fundamental en la explicación de grupos sociales, religiones, sistemas políticos y de los medios de comunicación. De ahí que al menos de manera parcial se plantee la posibilidad de realizar un análisis semiótico de las piezas gráficas que acompañaron los discursos de los candidatos que participaron en los debates que serán estudiados en esta investigación. Es posible pensar que esta técnica se convertirá en una herramienta para lograr mayor conocimiento de cómo ciertos procesos se presentan en la vida social de la gente, especialmente en tiempos de elecciones, qué efectos de sentido tienen sus construcciones, qué relaciones se pueden establecer entre aspectos estéticos y culturales o entre los perceptivos y sus usos sociales.

Palobra No. 13. Agosto de 2013 


\section{LO QUE PODRÍA ARROJAR ESTE RECORRIDO}

Los enfoques cualitativos en la investigación en ciencias sociales y específicamente en el estudio de los actores que confluyen en la comunicación política, permiten relacionar categorías conceptuales y ofrecer una comprensión más amplia de la problemática que se plantea. En este documento de trabajo más que presentar hipótesis se articulan sospechas, lecturas preliminares de una realidad que al vincularse con la teoría, permite analizar prácticas electorales en la ciudad, clientelismo político, promesas de campaña, mediaciones sociales, deliberación pública y ciudadanía, es decir, los aspectos medulares que bordeará esta investigación. Las sospechas, las aproximaciones, los referentes teóricos y metodológicos se han ido trazando, pero las respuestas a las preguntas que giran alrededor del clientelismo político en Cartagena se irán sistematizando con los resultados que arroje el ejercicio de campo y la articulación teórica. Por ahora solo es posible anticipar que la perspectiva de análisis se superpone a los prejuicios y examina el clientelismo como relacionamiento político y como una práctica que ha estado presente en todos los sistemas democráticos. El análisis de su institucionalización en la ciudad a partir de los procesos electorales de Alcaldía en el siglo XXI, con seguridad arrojará datos muchos más claros para entender la dinámica política, mediática y social de Cartagena durante el presente siglo y ampliar el recorrido que se ha emprendido en el estudio de este fenónemo en Colombia y Latinoamérica.

\section{BIBLIOGRAFÍA EXPLORADA}

Auyero, Javier (1996). La doble vida del clientelismo político. Revista Sociedad Nº (pp 31-56). Buenos Aires.

Auyero, Javier (1997). ¿Favores por votos? Estudio sobre clientelismo político contemporáneo. Editorial Losada, Buenos Aires.

Auyero, Javier (2001). La política de los pobres. Las prácticas clientelares del peronismo. Editorial Manantial, Buenos Aires.

Barbero, J. (1987). De los medios a las mediaciones. Barcelona: Gustavo Gili.

Bonilla, J. I. (2003), "Revistando el concepto de comunicación política. Apuntes para una discusión”, en Revista Mediaciones, núm. 3 (agosto-diciembre). 
Bonilla, J. I Iván y Patiño, G (Editores), Comunicación y política. Viejos conflictos, nuevos desafíos, Bogotá, Ceja. 2001.

Boissevain, J (1985). When de saint go marching out (cuando los santos salen de procesión): reflexiones sobre la decadencia del patronazgo en Malta. En Gellner y otros.

Bourdieu, Pierre (1993). El sentido de lo práctico. Taurus, Madrid, 1993.

Caciagli, Mario (1996). Clientelismo, corrupción y criminalidad organizada, Centro de Estudios Constitucionales, Madrid.

Comunicación y política. Viejos conflictos, nuevos desafíos, Bogotá, Centro Editorial Javeriano, 2001.

Corzo Fernández, Susana (2002). El clientelismo político como intercambio. Institut de Ciémnies politiques i socials, WP, No 206, Barcelona.

Dahl, Robert A. La poliarquía. Participación y oposición. Tecnos. Madrid, 1989.

Del Rey Morat6, J.; La comunicación política. El mito de las izquierdas y las derechas, EUDEMA, Madrid, 1998.

Del Rey Morat6, J.; “¿De qué hablamos cuando hablamos de comunicación política?”, en Revista Zer, Diciembre 1996.

Fals-Borda, O., Subversión y cambio social en Colombia. - Bogotá, Tercer Mundo. 1968

Farinetti, Mariana (1998), Clientelismo y protesta: cuando los clientes se rebelan. En Revista Apuntes de Investigación, Año II, No 2/3, pp 104-113, Cecyp, Buenos Aires.

Graziano, Luigi (1983). Introduction, en International Political Sciene Rewiew, vol. 4, pp 425-432, número monográfico sobre el clientelismo.

Gómez Buendía H. "Lo patológico y lo democrático del clientelismo" en revista Nueva sociedad nro.74, septiembre- octubre de 1984, pp. 91-95.

Hall, Anthony (1977). Patron-client relations. Concepts and terms, En Schmidt, Guasti, Lande and Scott.

Hall, S. (1981). "La cultura, los medios y el efecto ideológico", en Curran, James; Gurevitch, Michael y Woollacot, Janet (coords.), Sociedad y comunicación de masas, México: Fondo de Cultura Económica.

Palobra No. 13. Agosto de 2013 
Hall, Stuart. (1980) "Codificar y decodificar" en Culture, media and lenguage, London: Hutchinson. Trad. de Silvia Delfino

Kaufmann, Margarita. Comunicación Política. Konrad Adenauer Stiftung. Perú, 1994.

Kaufman, Robert R. (1974). The patron-client concept and macro politics. Comparative Studies in Society and History, Vol. 16, No. 3 (Jun., 1974), pp. 284-308, Cambridge University Press.

Lermarchand R. and Legg K (1972). Political clientelism, and development: a preliminary análisis. Comparative politics, Vol. 4, No. 2, pp. 149-178, University of New Cork.

Moreno Luz6n, Javier (1995). "Teoría del clientelismo y estudio de la política caciquil". En Revista: Revista de Estudios Políticos Clave: A Volumen: 89 Páginas, inicial: 191 final: 224.

Muñoz Alonso, A.; Política y nueva comunicación. El impacto de los medios en la vida política, Fundesco, Madrid, 1989.

O’Donnell, Guillermo (1997). Contrapuntos. Ensayos escogidos sobre autoritarismo y democratización. Paidós, Buenos Aires.

Potter, J. (1996), La representación de la realidad: discurso, retórica y construcción social, Barcelona, Paidós.

Sanchéz Ruiz, E. (2005) Medios de comunicación y democracia. Bogotá: Editorial Norma.

Santiago, G; Varela, A. Marketing político electoral para municipios. Editorial Crujía. Buenos Aires, 2007.

Sarmiento Anzola, L (2010). Cartagena de Indias, la Venus del Caribe. En: http://www.desdeabajo. info/ediciones/item/8233-cartagena-de-indias-la-venus-del-caribe.html

Sartori, G (1987). Elementos de teoría política. Cap. 4 Democracia. Alianza Editorial. Madrid.

Serrano, M. (1985) "La mediación de los medios de comunicación de masas", En M. De Moragas Spa (compilador) (1985). Sociología de la Comunicación, Barcelona: Gustavo Gili.

Schedler, A. En la Revista Mexicana de Sociología, número 66, enero-marzo, 2004, México, D. F., pp. 57-97. ISSN: 0188-2503/04/06601-03.

Schroter, B. Revista Mexicana de Sociología 72, núm. 1 (enero- marzo, 2010): 141-175. 
Scott, James (1985). El patronazgo como mito. En Gellner Ernest y otros.

Scott, James (1977). Patron client politics and politicalk change in Southeast Asia, en Schmidt, Guasti, Lande and Scott .

Schorr, Martín (2002). Mitos y realidades del pensamiento neoliberal: La evolución de la industria manufacturera argentina durante los años noventa, AAVV: Más allá del pensamiento único. Hacia una renovación de las ideas económicas en América Latina., Buenos Aires, FLACSO.

Thompson, J (1998), Los media y la modernidad, Barcelona, Paidós.

Torres, Pablo (2002). Votos, chapas y fideos. Clientelismo político y ayuda social. Ed de la campana, La Plata.

Ver6n, Eliseo (1992), «Interfaces. Sobre la democracia audiovisual evolucionada», en Ferry, JeanMarc y Wolton, Dominique (Editores), El nuevo espacio público, Barcelona, Gedisa. 